\title{
Vehicle Emissions and Their Impact on Humans
}

\author{
Magomadov I.Z.* Khanaliev G.I. Mamatsuev R.A. Apkarov I.A. Aisungurov N.D. \\ Sergiev S.S. Mamasurov S.H. Aptaev H.H.
}

\author{
Grozny State Oil Technical University named after Academician M.D. Millionshchikov, Grozny, Russia \\ *Corresponding author. Email: magomadov.isa@bk.ru
}

\begin{abstract}
The article deals with the following topics: vehicle emissions and their impact on humans; study of the mechanism of transport noise and its impact on humans; measures to improve the level of environmental safety: scales of transport and dispersion of substances in the atmosphere are given in table format; effect of impurities in the air on humans; health of the population depending on the level of air and soil pollution; assessment of the impact of water pollution on the health of the population.
\end{abstract}

\section{Keywords: road transport, environmental safety, atmosphere, toxic substances}

\section{INTRODUCTION}

Over the years, road transport has played an increasing role in the development of the country's economy and all other industries.

However, it should be noted that along with the positive role of the growth of the automobile fleet, there are also negative consequences of this trend associated with the process of motorization. These include environmental pollution harmful to human health, urban planning problems requiring the expansion of parking and traffic areas, increasing demand for petroleum products, etc. Negative consequences also include an increase in road traffic accidents, resulting in more deaths and injuries, as well as increased material damage from road traffic accidents.

Road traffic accidents have an impact on the economic and social development of many countries. At the national level, they cause economic losses equal to $1-3 \%$ of gross national product. According to the World Bank, global economic losses due to road accidents amount to more than 500 billion US dollars per year.

Every day, 90 people die and about 600 are injured on our country's roads as a result of these accidents. At the same time, about $8 \%$ of those injured are young people between the ages of 7 and 16. [2]

In Chechnya, where the leading role in providing transport communications is played by road transport - the only means of transport that connects the mountainous and flat parts of the republic - the most acute problem is also the provision of road traffic safety. Motor transport accounts for $63.4 \%$ of the total cargo traffic of the republic, $96.8 \%$ of the transported cargo and $76.6 \%$ of the transported passengers. [10]

The purpose of road transport is to ensure the safe transport of goods and passengers in the shortest possible time and "door-to-door". However, the higher the speed of the vehicle, the more likely it is that severe accidents will occur.

Exhaust gases of cars contain carcinogenic components - carbon and nitrogen oxides, hydrocarbons, aldehydes, sulfur dioxide, lead, bromine, phosphorus. These substances have a harmful effect on human health and adversely affect flora and fauna. According to a number of foreign studies, automobile transport accounts for about $50 \%$ of the total amount of hazardous substances emitted into the atmosphere (in cities - up to $70 \%$ ). The level of transport noise in cities is unacceptably high, it reaches 70-75 $\mathrm{dB}$ (at the norm for residential premises $40-50 \mathrm{~dB}$ during the day and $30-40 \mathrm{~dB}$ at night) [1].

Modern scientific researches and practical experience allow to explain the reasons of the above mentioned negative phenomena and to give recommendations on reduction and elimination of undesirable consequences of motorization. We can name three most important features of modern road transport that determine the low level of traffic safety:

- insufficient provision of road transport with roads corresponding in their parameters;

- insufficient isolation of traffic flows from other road users;

- the mass of the driver's profession, resulting in a low average level of qualification.

Lagging road construction from the growth of the automobile fleet is typical for almost all countries in the world. The disproportion between the growth of the vehicle fleet and the development of the street and road network is particularly noticeable in cities, where road construction is limited not only by financial possibilities, but also by the existing planning and development. When streets and roads are saturated with vehicles, all the negative phenomena of motorization are particularly noticeable. The growth of the automobile fleet and the 
volume of traffic leads to an increase in traffic intensity, which in the conditions of historically developed cities leads to the transport problem. This problem is particularly acute at the junctions of the street and road network (intersections of the cities with historical buildings). Traffic delays, queues and jams increase, resulting in fuel overruns and increased wear and tear on vehicle components and units. More than $30 \%$ of all traffic accidents are concentrated at intersections, which occupy a small part of the city territory. Analysis of the causes of accidents at intersections of city streets shows that ignoring the peculiarities of traffic flows in their design and development of recommendations on the organization of traffic leads to an increase in traffic accidents. As traffic intensifies, the probability of conflicts at intersections between road users also increases. Ensuring fast and safe traffic in modern cities requires the application of a set of measures of architectural, planning and organizational nature. Architecturally-planning measures include construction of new and reconstruction of existing streets, passages and highways, construction of transport intersections at different levels, etc. Organizational measures contribute to the regulation of traffic on the already existing street and road network. Such measures include the introduction of one-way traffic, circular traffic at intersections, organization of pedestrian crossings and pedestrian zones, parking lots, etc. [11].

\section{METHODS AND MATERIALS}

The environmental safety of a vehicle is understood to be its property to reduce the negative impact on the environment. Environmental safety covers all aspects of car use. The following are the main environmental aspects related to the use of the vehicle. [4]

Loss of useful land area. The land necessary for driving and parking shall be excluded from the use of other sectors of the national economy. The total length of the world network of paved roads exceeds 10 million $\mathrm{km}$, which means the loss of more than 30 million hectares. The expansion of streets and squares leads to the expansion of city territories and extension of all communications.

Pollution of the atmosphere. Most of the harmful impurities scattered in the atmosphere are the result of car exploitation. The average power engine emits about $10 \mathrm{~m}^{3}$ of emission gases into the atmosphere in one day of operation, which include carbon monoxide, hydrocarbons, nitrogen oxides and many other toxic substances.

Use of natural resources. Millions of tons of high quality materials are used to produce and operate cars, which leads to the depletion of their natural resources. With the exponential growth in per capita energy consumption that characterizes industrialized countries, there will soon be a moment when existing energy sources will not be able to meet human needs. A significant share of energy consumption is consumed by cars, which engines efficiency is $0.3 \ldots 0.35$. Consequently, $65 . . .70 \%$ of the energy potential is not used.
Noise and vibrations. The level of noise, long tolerated by a person without harmful consequences, is $80 \ldots 90 \mathrm{~dB}$. On the streets of big cities and industrial centers the noise level reaches $120 \ldots 130 \mathrm{~dB}$. Soil fluctuation caused by the movement of cars has a damaging effect on buildings and structures.

To protect people from the harmful effects of vehicle noise, various techniques have been applied: improvement of the design of cars, noise protection structures and green areas along busy urban highways, organization of a traffic regime when the noise level is the lowest.

The destruction of flora and fauna. Vehicles working off-roads compacted the topsoil, destroying the vegetation cover. Gasoline and oils spilled on the ground kill plants. Lead oxides in vehicles' emissions infect trees and shrubs. Fruits of fruit trees growing near roads with heavy traffic are not to be eaten. Flowers growing on the dividing strips are also poisonous. Thousands of animals, millions of birds, countless insects die under the wheels of cars every year. [6]

Radio interference. Radio interference is created when the ignition system of the car engine is running. Special devices are provided in ignition systems to suppress them. Road traffic regulations prohibit the operation of a vehicle with a faulty radio noise control system.

Suspended particles. Suspended particles. Dust particles from 0.01 to $100 \mu \mathrm{m}$ are classified as follows: more than $100 \mu \mathrm{m}$ - settling, less than $5 \mu \mathrm{m}$ - hardly settling.

The particles of the first type are harmless, as they precipitate quickly either on the surface of the earth, or in the upper respiratory tract. Particles of the second type enter deep into the lungs. The presence of compounds of carbon, hydrocarbons, aromatic substances, arsenic, mercury, etc. in the lungs due to the penetration of dust, as well as a connection with the frequency of cancer, chronic respiratory disease, asthma, bronchitis, emphysema of the lungs. The rate of carbon black in OG is $0.8 \mathrm{~g} / \mathrm{m}^{3}$.

Sulfuric anhydride. It has an adverse effect on mucous membrane of upper airways, causes bronchial congestion. Starting from $500 \mathrm{mct} / \mathrm{m}^{3}$, complications are observed in bronchitis patients, $200 \mathrm{mct} / \mathrm{m}^{3}$ causes an increase in asthmatic attacks.

Nitrogen oxides. Nitrogen dioxide and phytochemical derivatives are by-products of diesel engine working processes. They have an effect on the lungs and visual organs. Starting from $150 \mathrm{mct} / \mathrm{m}^{3}$, with prolonged exposure there is a violation of respiratory functions Nitrogen oxides irritate the mucous membrane of the eyes and nose, destroy the lungs.

$\mathrm{NO}_{\mathrm{x}}$ is thought to be 10 times more toxic than $\mathrm{CO}$. $\mathrm{N}_{2} \mathrm{O}$ works as a drug. The norm of $\mathrm{NO}_{\mathrm{x}}$ in the air is 0,1 $\mathrm{mg} / \mathrm{m}^{3}$.

NOx is thought to be 10 times more toxic than CO. $\mathrm{N} 2 \mathrm{O}$ acts as a drug. The norm of NOx in air is $0.1 \mathrm{mg} / \mathrm{m} 3$.

Ozone. The increase of nitrogen oxides and hydrocarbons concentration under the influence of solar radiation generates photochemical smog (ozone, PAN, etc.) Background ozone concentration in nature is $20-40$ 
$\mathrm{mct} / \mathrm{m}^{3}$. At $200 \mathrm{mct} / \mathrm{m}^{3}$ there is a noticeable negative impact on the human organism

Carbon monoxide. When burning fuel under conditions of lack of air, $\mathrm{CO}$ is generated during the operation of car engines.

$\mathrm{CO}$ is formed on the piston surface and on the cylinder wall, in which the activation does not occur due to intense heat dissipation into the walls, poor fuel spraying and dissociation of $\mathrm{CO} 2$ on $\mathrm{CO}$ and $\mathrm{O} 2$ at high temperatures [3].

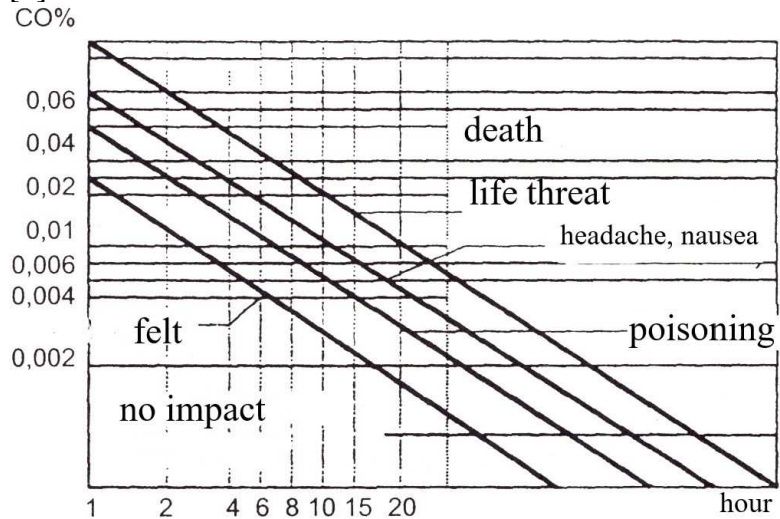

Figure 1 Effects of $\mathrm{CO}$ on the human body

Translation: death, life threat, headache, nausea, felt, poisoning, no impact, hour

When combined with hemoglobin, breathable air enters the blood, preventing the saturation of blood with oxygen, and therefore tissues, muscles and brain. It causes loss of vision, orientation in space and reactions. $\mathrm{CO}$ causes nervous system disorders, headache, weight loss, vomiting. The greatest danger of $\mathrm{CO}$ poisoning are people who are in closed, poorly ventilated rooms next to a running engine. It is especially dangerous to be found in the cabin of a car with an airtight exhaust system. It is also not recommended to stay in the cab of a vehicle whose engine is constantly running at idling speed for a long time. Due to the accumulation of $\mathrm{CO}$ around the vehicle, it is possible to increase the concentration of $\mathrm{CO}$ in the cab to values that cause loss of consciousness (Fig. 1).

\section{RESULTS}

Motor engines annually emit into the atmosphere 20-27 million tons of carbon monoxide; $2.0-2.5$ million tons of hydrocarbons; 6-9 million tons of nitrogen oxide; up to 190 tons of sulphur compounds; up to 100 thousand tons of soot; 13 thousand tons of heavy metal compounds; 200-230 million tons of hydrocarbon dioxide.[8].

The total volume of emissions of regulated harmful substances by the ATS fleet in terms of $\mathrm{CO}$ is about 300-400 million conventional tons per year.

The following types of pollutants are emitted from combustion chambers of thermal engines: nitrogen oxides $\left(\mathrm{NO}_{\mathrm{X}}\right)$, carbon monoxide (CO), unburned hydrocarbons
$\left(\mathrm{C}_{\mathrm{x}} \mathrm{H}_{\mathrm{y}}\right)$, sulfur oxides $\left(\mathrm{SO}_{\mathrm{x}}\right)$, solid particles, including aerosols, as well as carbon dioxide or carbon dioxide $\left(\mathrm{CO}_{2}\right)$.

The principal scheme of the main toxic components formation in gasoline and diesel combustion engines is presented in Fig. 2.

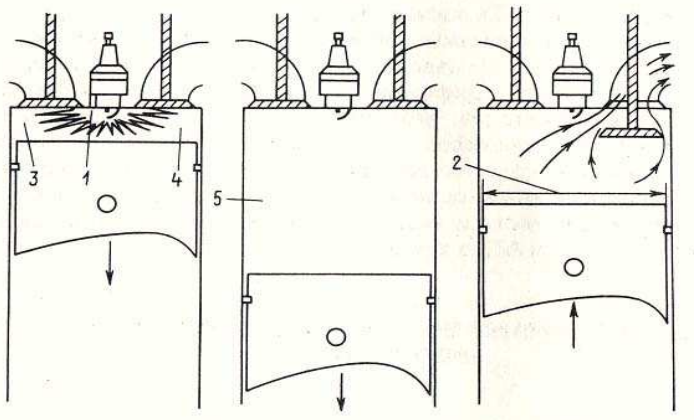

Figure 2 Scheme of main pollutants formation in automobile engines: 1 - formation of NOx at hightemperature oxidation of air nitrogen; 2 - "scraping" of oil film walls (formation of $\mathrm{C}_{\mathrm{x}} \mathrm{H}_{\mathrm{y}}$ and solid particles); 3 - flame extinguishing near the cylinder walls (formation of $\mathrm{C}_{\mathrm{x}} \mathrm{H}_{\mathrm{y}}$ ); 4 - formation of local "overcharged" zones in the combustion chamber (formation of $\mathrm{CO}$ ).[9]

When considering the environmental impact of certain types of vehicles, it should be noted that the dominant share of emissions (54\%) of all harmful substances belongs to trucks. About $50 \%$ of lead compounds enter the atmosphere from cars and two-thirds of nitrogen dioxide comes from trucks [7].

It should be noted that harmful substances during the operation of mobile vehicles enter the air in volumes that depend on the operating modes of the engines. Here the conditions of motor transport exploitation and the relief of the road play a major role. For example, during acceleration and braking in exhaust gases the content of carbon monoxide increases by almost 8 times. The minimum amount of carbon oxide is emitted at a uniform vehicle speed of $60 \mathrm{~km} / \mathrm{h}$.

In addition to meteorological factors for self-cleaning of the atmosphere, some components of harmful emissions from road transport are involved in the processes of interaction with the components of the air environment, resulting in the generation of new harmful substances (secondary air pollutants). The pollutants enter into physical, chemical and photochemical interactions with the air components.

\section{CONCLUSION}

The sensitivity of a population to air pollution depends on a large number of factors, including age, gender, general health, nutrition, temperature and humidity, etc. The elderly, children, the sick, smokers with chronic 
bronchitis, coronary artery disease, asthma are more exposed to the risk. [5]

The problem of atmospheric air composition and pollution from motor vehicle emissions is becoming more

Table 1 Atmospheric transport and dispersion rates and more urgent and public health depends on solving this problem.

\begin{tabular}{|l|c|c|}
\hline \multicolumn{1}{|c|}{ Harmful substances } & Transfer distance, $\mathbf{k m}$ & Time of dissipation or transformation, $\boldsymbol{h o u r}$ \\
\hline $\mathrm{NO}$ & 10 & 1 \\
\hline $\mathrm{NO}_{2}, \mathrm{SO}_{2}$ & 100 & 48 \\
\hline$\Pi$ HH, $\mathrm{HNO}$ & 1000 & 96 \\
\hline $\mathrm{H}_{2} \mathrm{SO}_{4}$ & 1000 & up to 90000 \\
\hline $\mathrm{CH}_{4}$ & Earth scale & \\
\hline
\end{tabular}

Table 2 Airborne impurity effect

\begin{tabular}{|c|c|c|c|}
\hline \multirow{2}{*}{ Exposure effect } & \multicolumn{3}{|c|}{ Content, $m g / m^{3}$} \\
\hline & CO & $\mathrm{SO}_{2}$ & $\mathbf{N O}_{\mathbf{x}}$ \\
\hline A few hours with no noticeable impact & 115 & 6 & 15 \\
\hline $\begin{array}{l}\text { Signs of mild poisoning or irritation of the mucous membranes } \\
\text { after } 2-3 \text { hours }\end{array}$ & $115-575$ & 130 & 20 \\
\hline Poisoning in $30 \mathrm{~min}$ & $2300-3500$ & $210-400$ & 100 \\
\hline Life-threatening on short-term exposure & 5700 & 1600 & 150 \\
\hline
\end{tabular}

Table 3 Status of the health of population in consideration of the enterprise limitation of air and animal special (machine ratio)

\begin{tabular}{|l|c|c|}
\hline \multicolumn{1}{|c|}{ Expected health condition } & Air & Soil \\
\hline Without negative changes & 1 & 1 \\
\hline Changes in health in some indicators & $2-3$ & $4-10$ \\
\hline Expressed functional shifts & $4-7$ & $20-120$ \\
\hline Growth of specific and non-specific morbidity & $8-10$ & $120-200$ \\
\hline Acute and chronic poisoning & 100 & $200-1000$ \\
\hline Lethal intoxications & 500 & \\
\hline
\end{tabular}

Table 4 Assessment of the impact of water pollution on public health

\begin{tabular}{|l|c|c|}
\hline \multicolumn{1}{|c|}{ The degree of contamination } & Frequency of excess of MPC & Contamination index \\
\hline Tolerable & 1 & 1 \\
\hline Moderate & $2-3$ & 2 \\
\hline High & $4-10$ & 3 \\
\hline Extremely high & 100 & 1 \\
\hline
\end{tabular}




\section{REFERENCES}

[1] L.P. Bronstein, Modern means of atmospheric pollution measurement, Giprometeoizdat, St. Petersburg, 2009.

[2] V.N. Lukanina, K.-H. Lenz, Highways: safety, environmental problems, economics (RussianGerman experience), Logos, Moscow, 2002, 624 p.

[3] V.N. Denisov, V.A. Rogalev, Problems of motor transport ecologization, ECO, St. Petersburg, 2004, $194 \mathrm{p}$.

[4] V.I. Korobkin, Ecology, Moscow, 2006, 465 p.

[5] B. Rudenko, Price of civilization, Sci. and life 7 (2004) 32-36.

[6] Y. Shishkov, The fragile ecosystem of the Earth and irresponsible humanity, Sci. and life 12 (2004) 2-11.

[7] N.G. Kirillov, Problems of ecology of motor transport of Russia, Moscow, 2007.

[8] G.A. Guk, A.V. Bogachev, Impact of the motor transport complex on environment, Maykop, 2007, p. 10.
[9] D.I. Guryanov, Ecologically clean transport: development directions, Engineer, technologist, worker 2 (2001) 12-14.

[10] S.P. Davydova, Motor transport continues to pollute the environment, ECiP 7 (2000) 40-41.

[11] S.P. Zhukov, Natural gas - motor fuel of XXI century, Industry today 2 (2001) 12.

[12] E. Krinitskiy, Ecology of motor transport should be determined by Federal Law, Automobile transport 9 (2000) 34-37.

[13] A.R. Shakirova, Development of urban passenger transport, Theoretical and applied issues of modern geography, Materials of All-Russian youth schoolseminar, Deltaplane Ltd. Publ. House, Tomsk, 2005, pp. 36-42.

[14] E.P. Yasenkov, Elements of automobile complex and their influence on environment, Automobile industry 8 (2007) 42. 